\title{
The mental health effects of visa insecurity for refugees and people seeking asylum: a latent class analysis
}

\author{
Elizabeth A. Newnham ${ }^{1,2,3} \cdot$ April Pearman $^{4} \cdot$ Stephanie Olinga-Shannon $^{4} \cdot$ Angela Nickerson $^{5}$
}

Received: 7 January 2018/Revised: 9 April 2019 / Accepted: 7 May 2019/Published online: 28 May 2019

(C) Swiss School of Public Health (SSPH+) 2019

\begin{abstract}
Objectives Current regional conflicts are creating a surge in forced migration, and heightened visa restrictions are increasingly being applied. The current study aimed to examine the relationship between visa insecurity and psychological outcomes within a large clinical sample of refugees and people seeking asylum in Australia.

Methods The sample comprised 781 clients (53.9\% male, 16-93 years) attending a clinic for trauma survivors. Country of birth was most frequently identified as Afghanistan (18.1\%), Iraq (15.3\%) and Iran (15.1\%). The Hopkins Symptom Checklist was administered at admission.

Results Latent class analyses identified four groups varying in severity of symptoms, namely very high (16.1\%), high $(38.1 \%)$, moderate $(31.5 \%)$, and low $(14.3 \%)$. People with insecure visa status were at least five times more likely to report high $(\mathrm{OR}=5.86, p<0.001)$ or very high $(\mathrm{OR}=5.27, p<0.01)$ depression and anxiety symptoms than those with permanent residency. Women were almost twice as likely to report high $(\mathrm{OR}=1.96 p<0.01)$ or very high $(\mathrm{OR}=1.96$, $p<0.05$ ) symptoms.

Conclusions The findings suggest that temporary visas play a significant role in psychological distress and that timely immigration processing has important implications for health outcomes.
\end{abstract}

Keywords Refugee $\cdot$ Asylum $\cdot$ Migration $\cdot$ Depression · Anxiety · Gender

\section{Introduction}

The complexities of refugee resettlement extend beyond the journey to safety. At a time when the world is witnessing a crisis in mass displacement (UNHCR 2018), the health implications of migration are multifaceted (Hollings et al. 2012). Many major refugee-producing countries are

Elizabeth A. Newnham

Elizabeth.newnham@curtin.edu.au

1 School of Psychology, Curtin University, GPO Box U1987, Perth 6845, Australia

2 FXB Center for Health and Human Rights, Harvard T.H. Chan School of Public Health, Boston, USA

3 School of Psychological Science, The University of Western Australia, Perth, Australia

4 Association for Services to Torture and Trauma Survivors (ASeTTS), Perth, Australia

5 School of Psychology, University of New South Wales, Sydney, Australia among the most visa-restricted, which can lead to a reliance on alternative and dangerous migration routes to avoid immigration controls (Steel et al. 2011a). To dissuade movement across borders, many governments have imposed interception measures such as extensive border controls, immigration detention, and visa restrictions (Fazel et al. 2014; Hollings et al. 2012). These measures have been widely implemented to avoid transitory movement and resettlement not only in high-income nations (Steel et al. 2011a), but also across a number of low- and middle-income nations (Fazel et al. 2014).

Increasingly stringent migration policies have been linked to a range of damaging physical and psychological effects. In detention settings across Australia, the United Kingdom, and USA, increased rates of suicide, self-harm, voluntary starvation, post-traumatic stress disorder (PTSD), and developmental regressions have been consistently documented (Dudley et al. 2011; Robjant et al. 2009; Steel et al. 2004). The effects of restrictive visa policies have received less attention. However, emerging evidence 
is beginning to illuminate the role of temporary visa status on mental health outcomes. Where post-migration stressors have been considered in the assessment of refugee mental health, temporary visas, visa cancellation, and long processing times have each demonstrated significant associations with psychological distress (Hocking et al. 2015; Laban et al. 2004; Morgan et al. 2017). Among Iraqi refugees in Australia, symptoms consistent with a clinical diagnosis of depression were reported by $46 \%$ of Iraqi refugees on a temporary protection visa (TPV) compared to $25 \%$ of refugees with permanent visa status. Similarly, among refugees from Iran and Afghanistan, those with TPVs reported a worsening trajectory of depression and anxiety and maintenance of high PTSD scores over a twoyear follow-up, whereas those with permanent visas reported improvements in depression and anxiety and low levels of PTSD (Steel et al. 2011b). Correspondingly, conversion from a TPV to permanent residency was associated with significant improvements in depression and PTSD symptoms, mediated by reductions in living difficulties among Mandean refugees (Nickerson et al. 2011), suggesting that access to permanency status has potential for longer-term mental health benefits. However, research to date has been conducted with small sample sizes and with participants from a limited number of countries of origin, restricting our understanding of the effects of visa policy for diverse communities.

Visa insecurity compounds the range of daily adversities associated with resettlement. Challenges related to poverty, unemployment, discrimination, and separation from family members have detrimental effects for mental health (Carswell et al. 2011; Slobodin et al. 2018). Reductions in postmigration living difficulties have been associated with improved depression and anxiety outcomes for refugees in high-income countries (Schick et al. 2018), indicating the importance of timely support for accessing employment, establishing safe accommodation, and fostering a sense of inclusion in the community. While the visa process is often highlighted as a salient stressor, visa status has frequently been analysed as part of a composite scale of post-migration living difficulties. Thus, an examination of the effects of visa insecurity for people seeking asylum is needed to determine its specific role in mental health outcomes for resettled populations.

Building upon the growing evidence base for the mental health effects of visa insecurity, the present study aimed to examine the relationship between visa status and psychological distress among a large clinical sample of people seeking asylum in Australia. In order to compare groups with different visas, data were collected for refugees and asylum seekers with the following status: (1) permanent residency visas or citizenship, (2) temporary bridging visas awaiting assessment of their asylum claims, and (3) people whose asylum claims had been rejected, and/or were awaiting deportation. In line with prior research and the clinical perceptions of torture rehabilitation service providers, it was hypothesized that visa insecurity would be associated with higher rates of depression and anxiety in a heterogeneous sample.

\section{Methods}

\section{Immigration policy context}

Australia's refugee visa quota remained relatively stable during the study timeframe (2009-2015). Six thousand refugee visas were granted each year, with the exception of 12,000 visas granted in 2012 (Karlsen 2016). In contrast, policies pertaining to asylum varied. People arriving by boat to seek asylum in Australia were subject to mandatory detention, and those who were determined to be refugees were eligible for 3-year temporary protection visas (Phillips and Spinks 2013). The period between 2012 and 2013 saw a rapid increase in the number of people attempting to reach Australia by boat, with more than 400 boats and 25,000 people arriving in one year (Phillips 2014). This group-now known as the "legacy caseload"-was subject to a number of policy changes designed to discourage people from risking the journey by boat, including extended delays to the processing of their refugee claims, removal of access to permanent residence, and a substantial reduction in funding for legal assistance (Kenny et al. 2016). During this period, asylum seekers who had originally been held in immigration detention were released into the community on bridging visas without work rights, although work rights were reinstated in December 2014. For those without work, the government provided limited financial and case management support (Kenny et al. 2016).

\section{Participants}

Participants comprised refugees and people seeking asylum who accessed treatment related to a history of torture and trauma at an Australian not-for-profit rehabilitation clinic. All participants were living within the community, although some may have previously been held in immigration detention. Psychological services at the clinic did not require referral from a general practitioner, although this was a common referral pathway and provided free of charge to the client. Other pathways included referral by settlement services, caseworkers, education providers, mental health practitioners, and self-referral. The sample comprised 781 males and females aged 16 years and older. All data were collected in standard clinical care procedures 
for clients who sought torture and trauma counselling. The sample is therefore a sub-sample of the clinical population of refugee and asylum seeking individuals in Australia.

All participants provided informed consent for the clinical use of their outcome data, as deidentified data for evaluation and research purposes. Participants were given opportunities to opt out of the outcome assessment process, should it for example, exacerbate trauma symptoms or reflect memories of interrogation processes too closely. Reasons for not completing the measures (and whether the decision to opt out was made by the clinician or the participant) were not recorded. Ethics exemption was granted by the University of Western Australia Human Research Ethics Committee.

\section{Measures}

\section{Demographics}

Demographic items that covered gender, age, visa status, country of birth, date of arrival in Australia, and use of an interpreter in session were collected by the service at the point of referral or during assessment. Socio-economic status was determined by suburb rankings converted to percentiles, calculated in accordance with the Australian Bureau of Statistics Index of Relative Socio-economic Advantage and Disadvantage.

\section{Depression and anxiety symptoms}

The Hopkins Symptom Checklist-25 (HSCL-25; Hesbacher et al. 1980) is comprised of 25 items measuring participants' depression and anxiety symptoms. Responses were given on a four-point scale ranging from 1, "not at all" to 4, "extremely". Scores on the first ten items were summed and then divided by the number of questions answered to give a mean anxiety score. Scores on the subsequent 15 items were scored in the same way to give a mean depression score. An overall score can be created from all 25 responses using the same technique. A score on either of the subscales or on the total scale greater than, or equal to, 1.75 is considered symptomatic. For the latent class analysis conducted in this study, items were dichotomized to indicate the presence (scoring 3 or 4 ) or absence (scoring 1 or 2 ) of each symptom. All items were included in the analysis, consistent with prior use of the HSCL-25 in refugee samples (Hollifield et al. 2002). While this scale was not originally designed for refugee populations, it has been found to have good reliability and validity in clinical refugee samples (Hollifield et al. 2002; Vonnahme et al. 2015). It is widely used in refugee mental health assessment and in torture rehabilitation centres globally, and numerous high-quality translated versions are available.
There was high internal reliability for the depression subscale $(\alpha=0.90)$, anxiety subscale $(\alpha=0.91)$, and total scale $(\alpha=0.95)$ in this sample.

\section{Setting and procedure}

The treatment clinic was a non-government, not-for-profit organization that provides individual clinical counselling, family and community services for people from refugee and asylum seeker backgrounds in Perth, Australia. All clients had a background of trauma or torture exposure. Clinicians held qualifications in the areas of psychology, social work, and counselling, and all received specialist training for working with individuals affected by torture and trauma. Comprehensive induction and ongoing professional development were provided to all clinicians in the core competency areas of: understanding the refugee/asylee experience, working effectively with interpreters, cross cultural counselling, managing compassion fatigue, and a range of best practice therapeutic modalities for working with survivors of extreme violence. Regular clinical supervision was provided to all staff.

Standardized assessments were administered as a routine aspect of the clinical assessment conducted within the first three sessions. Clinicians assisted with administering the questionnaires in English, with an interpreter where necessary. Where self-report was possible, clients completed the measure in English or a translated version in their own language. Questionnaires were not completed if the client declined or the clinician deemed the process to be inappropriate, for example, if the client was experiencing acute psychosis, was at risk of suicide, or the process too closely reflected the client's prior experiences of trauma. Data were collected between September 2009 and September 2015.

\section{Data analysis}

The study aimed to identify groups of individuals who shared profiles of responses on the HSCL-25. A comparison of demographics was conducted in SPSS Version 24. Latent class analysis (LCA) was conducted in MPLUS 6 (Muthén and Muthén 2010), using a maximum likelihood estimator. LCA is a person-centred form of finite mixture modelling, used to identify unobserved latent variables that represent subgroups of individuals within cross-sectional data (Marsh et al. 2009; Muthén and Muthén 2010; Newnham et al. 2017). LCA estimates a model for the population from which sample data are taken, and an individual's probability of belonging to a certain group is estimated. The analysis classifies individuals into independent and uncorrelated latent classes, where the optimal number of classes is chosen based on a combination of fit 
statistics (Pastor et al. 2007). In the current study, participants were grouped on the basis of symptom profiles, assessed across all items of the HSCL-25. Models are estimated sequentially (i.e. a one-class model, a two-class model, etc.) until a model with optimal fit is derived.

Fit statistics included the Bayesian Information Criteria (BIC; Marsh et al. 2009) which measure the parsimony of the model, where a lower BIC indicates better model fit (Nylund et al. 2007). Log-likelihood values were also calculated to determine better model fit (Pastor et al. 2007), while the Vuong-Luo-Mendell-Rubin likelihood-ratio test (LMR-LRT) and the parametric bootstrapped likelihoodratio test (BLRT) assessed the statistical significance of changes in models indicating fit via increasing number of classes (Marsh et al. 2009; Nylund et al. 2007). Finally, posterior probabilities (probability of membership in the most likely class) and entropy (a measure of the quality of classification into classes) were examined in the model with the most reliable statistics. In relation to conditional probabilities, values $\geq 0.60$ were considered to represent a high probability of symptom endorsement in a given class, values $\leq 0.15$ were considered to represent a low probability of symptom endorsement in this class, and values $\leq 0.59$ and $\geq 0.16$ were considered to represent a moderate probability of symptom endorsement in a given class (Galatzer-Levy et al. 2013).

Multinomial logistic regression was then conducted in MPLUS (Muthén and Muthén 2010). A model-based approach was implemented to investigate predictors of class membership. Gender, age, socio-economic status, requiring use of an interpreter in sessions, years in Australia, and visa status were included as predictors in the regression model within MPlus. Visa status was coded at two levels $(0=$ Permanent Resident, with or without citizenship, 1 = Asylum seeker on a temporary bridging visa, awaiting processing of their refugee application or awaiting deportation). Five participants had data missing on these variables and were excluded from the analyses.

\section{Results}

\section{Sample characteristics}

The sample comprised 781 participants ( $53.9 \%$ male), aged $16-93$ years $($ mean $=37.5, \mathrm{SD}=11.9)$. Forty-two per cent were married, $25.6 \%$ single, $6.4 \%$ widowed and $4.9 \%$ divorced. Country of birth was most frequently listed as Afghanistan (18.1\%), Iraq (15.3\%), Iran (15.1\%), Myanmar (8.2\%), Sri Lanka (7.6\%), and Sudan (4.7\%). People born in Sri Lanka and Pakistan were more often represented in the insecure visa groups (see Table 1). The three most common primary languages were Arabic (19.6\%), Persian (15.9\%), and English (13.2\%). A majority of clients required an interpreter during their assessment sessions $(74.8 \%)$.
Table 1 Demographic characteristics by immigration status for a clinical sample of refugees and asylum seekers in Australia, 2009-2015 $(n=781)$

\begin{tabular}{llll}
\hline & $\begin{array}{l}\text { Permanent visa/citizen } \\
(n=621)\end{array}$ & $\begin{array}{l}\text { Bridging visa } \\
(n=105)\end{array}$ & $\begin{array}{l}\text { Awaiting assessment/ } \\
\text { deportation }(n=55)\end{array}$ \\
\hline Female gender $n(\%)$ & $307(49.4 \%)$ & $33(31.4 \%)$ & $20(36.4 \%)$ \\
Age mean (SD) & $38.19(12.18)$ & $35.18(11.12)$ & $33.78(8.97)$ \\
SES mean (SD) & $38.96(70.91)$ & $54.71(97.25)$ & $60.05(131.47)$ \\
Marital status $n(\%)$ & & & \\
Single & $133(21.4 \%)$ & $45(42.9 \%)$ & $22(40 \%)$ \\
Married & $267(43.0 \%)$ & $35(33.3 \%)$ & $28(50.9 \%)$ \\
Defacto partnership & $6(1.0 \%)$ & $2(1.9 \%)$ & 0 \\
Divorced & $34(5.5 \%)$ & $3(2.9 \%)$ & $1(1.8 \%)$ \\
Separated & $26(4.2 \%)$ & $4(3.8 \%)$ & $2(3.6 \%)$ \\
Widowed & $45(7.2 \%)$ & $4(3.8 \%)$ & $1(1.8 \%)$ \\
Country of birth $n(\%)$ & & & $4(7.3 \%)$ \\
Afghanistan & $127(20.5 \%)$ & $10(9.5 \%)$ & $11(20.0 \%)$ \\
Iran & $87(14.0 \%)$ & $20(19.0 \%)$ & $3(5.5 \%)$ \\
Iraq & $110(17.7 \%)$ & $6(5.7 \%)$ & 0 \\
Myanmar & $62(10.0 \%)$ & $2(1.9 \%)$ & $4(7.3 \%)$ \\
Pakistan & $2(0.3 \%)$ & $6(5.7 \%)$ & $14(25.5 \%)$ \\
Sri Lanka & $14(2.3 \%)$ & $31(29.5 \%)$ & 0 \\
Sudan & $37(6.0 \%)$ & 0 & \\
\hline
\end{tabular}

$n$ sample size, $S D$ standard deviation, $S E S$ socio-economic status 


\section{Visa status}

Within the sample, $79.5 \%$ reported holding a permanent resident visa or had attained Australian citizenship. Bridging visas were held by $13.4 \%$ of the sample. Bridging visas were a temporary visa granted with restricted employment and healthcare access, and no capacity to reunite with family members or leave the country. Asylum seekers without visas or awaiting deportation comprised $7.0 \%$ of the sample.

\section{Symptom profiles}

Table 2 presents fit statistics for the LCA models with one to five classes. Entropy was relatively strong for all classes.
Classes exhibited substantial decreases in the AIC and SSBIC up until four classes. A four-class solution yielded a statistically significant VLMR-LRT and LMR-LRT indicating that this model fit the data significantly better than the three-class solution. Conversely, the VLMR-LRT and LMR-LRT statistics were not significant for the five-class model, indicating that the five-class model was not superior to the four-class model. Thus, the four-class model was retained.

The four profiles spanned the range of HSCL scores and depicted increasing levels of severity across the groups (see Fig. 1). Conditional probabilities for each of the classes in the four-class solution for the HSCL items are presented in Table 3. Participants in the very high symptoms class $(16.1 \%)$ had a high probability of all anxiety and

Table 2 Latent class analysis fit indices for profiles on the Hopkins Symptom Checklist for a clinical sample of refugees and asylum seekers in Australia, 2009-2015 $(n=781)$

\begin{tabular}{llllllr}
\hline & AIC & BIC & SS-BIC & Entropy & VLMR-LRT & LMR-LRT \\
\hline 1 Class & $24,853.81$ & $24,970.26$ & $24,890.87$ & & & \\
2 Class & $21,380.47$ & $21,618.03$ & $21,456.08$ & 0.908 & $<0.001$ & $<0.001$ \\
3 Class & $20,763.98$ & $21,122.65$ & $20,878.13$ & 0.853 & $<0.001$ & $<0.001$ \\
4 Class & $20,560.65$ & $21,040.42$ & $20,713.35$ & 0.838 & 0.017 & 0.018 \\
5 Class & $20,440.94$ & $21,041.83$ & $20,632.19$ & 0.816 & 0.134 & 0.137 \\
\hline
\end{tabular}

AIC Akaike information criterion, BIC Bayesian information criterion, SS-BIC sample size adjusted Bayesian information criterion, VLMR-LRT Vuong-Lo-Mendell-Rubin likelihood-ratio test, LMR-LRT LoMendell-Rubin likelihood-ratio test

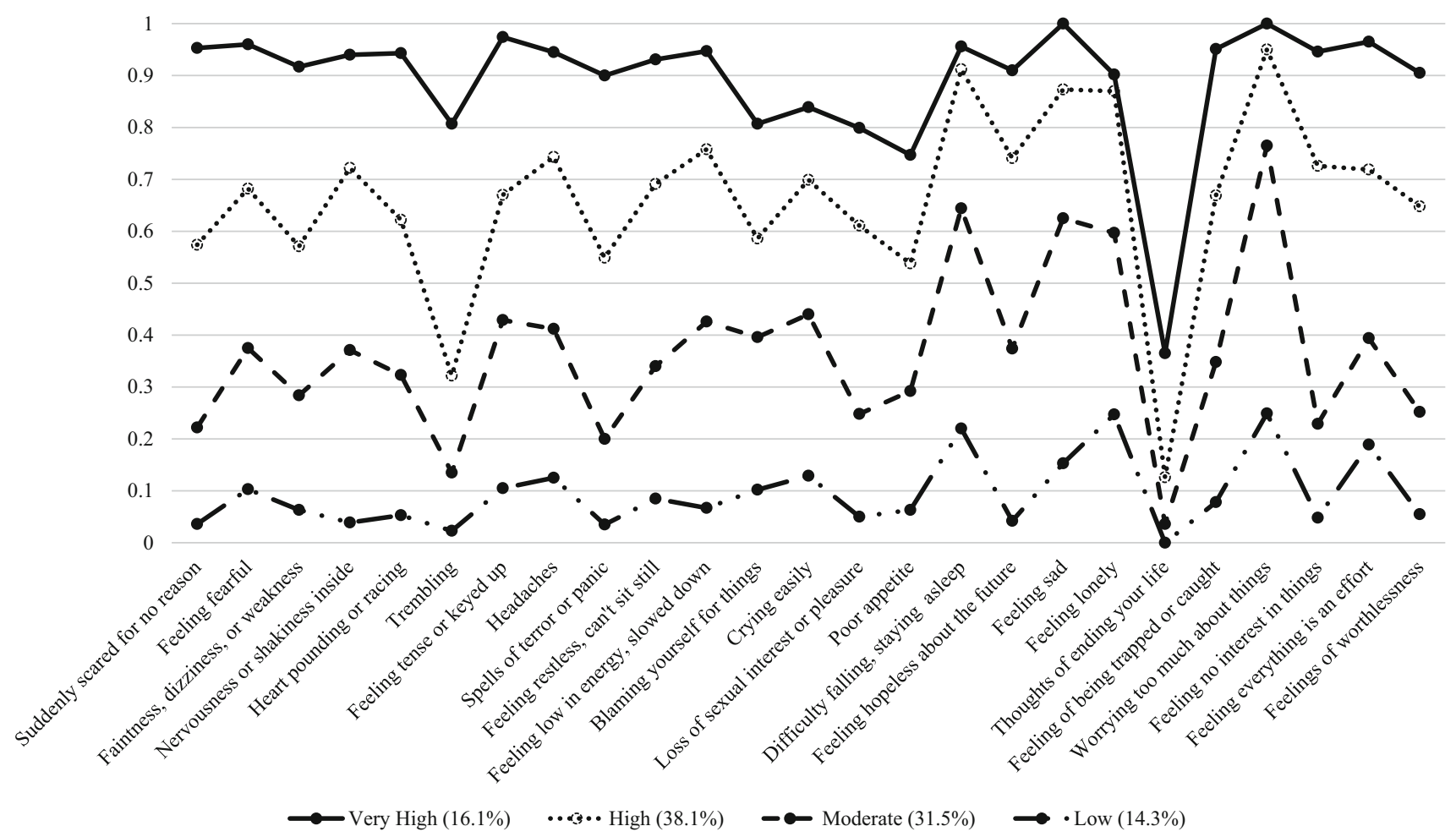

Fig. 1 Four latent classes emerging from the 25-item Hopkins Symptom Checklist among a clinical sample of refugees and asylum seekers in Australia 2009-2015 $(n=781)$ 
Table 3 Conditional probabilities of class membership by Hopkins Symptom Checklist items for a 4-class solution, for a clinical sample of refugees and asylum seekers in Australia, 2009-2015 $(n=781)$

\begin{tabular}{llllr}
\hline & $\begin{array}{l}\text { Very high } \\
(16.1 \%)\end{array}$ & $\begin{array}{l}\text { High } \\
(38.1 \%)\end{array}$ & $\begin{array}{l}\text { Moderate } \\
(31.5 \%)\end{array}$ & $\begin{array}{l}\text { Low } \\
(14.3 \%)\end{array}$ \\
\hline Suddenly scared for no reason & $0.95(0.04)$ & $0.57(0.04)$ & $0.22(0.05)$ & $0.04(0.02)$ \\
Feeling fearful & $0.96(0.03)$ & $0.68(0.04)$ & $0.38(0.05)$ & $0.10(0.04)$ \\
Faintness, dizziness, weakness & $0.92(0.04)$ & $0.57(0.04)$ & $0.28(0.04)$ & $0.06(0.04)$ \\
Nervousness or shakiness & $0.94(0.03)$ & $0.72(0.04)$ & $0.37(0.05)$ & $0.04(0.03)$ \\
Heart pounding or racing & $0.94(0.03)$ & $0.62(0.05)$ & $0.32(0.05)$ & $0.05(0.02)$ \\
Trembling & $0.81(0.07)$ & $0.32(0.04)$ & $0.14(0.03)$ & $0.02(0.02)$ \\
Feeling tense or keyed up & $0.97(0.02)$ & $0.60(0.04)$ & $0.43(0.05)$ & $0.11(0.04)$ \\
Headaches & $0.95(0.03)$ & $0.74(0.03)$ & $0.41(0.05)$ & $0.13(0.04)$ \\
Spells of terror or panic & $0.90(0.04)$ & $0.55(0.04)$ & $0.20(0.04)$ & $0.04(0.02)$ \\
Feeling restless, cannot sit still & $0.93(0.03)$ & $0.69(0.04)$ & $0.34(0.05)$ & $0.09(0.03)$ \\
Low in energy, slowed down & $0.95(0.04)$ & $0.76(0.03)$ & $0.43(0.05)$ & $0.07(0.04)$ \\
Blaming yourself for things & $0.81(0.04)$ & $0.59(0.04)$ & $0.40(0.04)$ & $0.10(0.04)$ \\
Crying easily & $0.84(0.04)$ & $0.70(0.03)$ & $0.44(0.04)$ & $0.13(0.04)$ \\
Loss of sexual interest & $0.80(0.05)$ & $0.61(0.05)$ & $0.25(0.04)$ & $0.05(0.04)$ \\
Poor appetite & $0.75(0.05)$ & $0.54(0.04)$ & $0.29(0.04)$ & $0.06(0.03)$ \\
Sleep difficulties & $0.96(0.02)$ & $0.91(0.03)$ & $0.64(0.05)$ & $0.22(0.05)$ \\
Feeling hopeless for the future & $0.91(0.03)$ & $0.74(0.04)$ & $0.37(0.04)$ & $0.04(0.03)$ \\
Feeling sad & $1.00(0.01)$ & $0.87(0.03)$ & $0.63(0.04)$ & $0.15(0.06)$ \\
Feeling lonely & $0.90(0.03)$ & $0.87(0.03)$ & $0.60(0.04)$ & $0.25(0.07)$ \\
Thoughts of ending your life & $0.37(0.05)$ & $0.13(0.03)$ & $0.04(0.02)$ & $<0.001(0.01)$ \\
Feeling of being trapped & $0.95(0.03)$ & $0.67(0.05)$ & $0.35(0.04)$ & $0.08(0.04)$ \\
Worrying too much & $1.00(0.01)$ & $0.95(0.02)$ & $0.77(0.04)$ & $0.25(0.06)$ \\
Feeling no interest in things & $0.95(0.04)$ & $0.73(0.04)$ & $0.23(0.04)$ & $0.05(0.03)$ \\
Feeling everything is an effort & $0.97(0.03)$ & $0.72(0.04)$ & $0.39(0.04)$ & $0.19(0.05)$ \\
Feelings of worthlessness & $0.91(0.05)$ & $0.65(0.04)$ & $0.25(0.04)$ & $0.06(0.03)$ \\
\hline & & & & \\
& & & &
\end{tabular}

depression symptoms, with the exception of thoughts of ending your life, which evidenced a moderate probability. Participants in the high symptoms class (38.1\%) had a high probability of a number of anxiety symptoms (feeling fearful, nervousness or shakiness inside, heart pounding or racing, headaches, and feeling restless or cannot sit still), a high probability of all depression symptoms except blaming yourself for things and poor appetite (which evidenced moderate probabilities), and thoughts of ending your life (which evidenced a low probability). Participants in the moderate symptoms class $(31.5 \%)$ had a moderate probability of all symptoms, with the exception of thoughts of ending your life, which evidenced a low probability. Participants in the low symptoms class $(14.3 \%)$ had a low probability of all anxiety and depression symptoms, with the exception of sleep difficulties, feeling lonely, worrying too much about things and feeling that everything is an effort, which evidenced moderate probabilities.

\section{Variables associated with class membership}

A multinomial regression analysis conducted in MPLUS explored the relationship between depression and anxiety class membership, and a range of predictor variables (see Table 4). When compared to individuals in the lowsymptom group, those in the high-symptom group were more likely to be female $(B=0.67, S E=0.26, p=0.01)$, less likely to require an interpreter $(B=-0.65, S E=0.32$, $p<0.05)$, and more likely to report insecure visa status $(B=1.77, S E=0.44, p<0.001)$. Similarly, individuals in the very-high-symptom group were more likely to be female $(B=0.77, S E=0.31, p<0.05)$ and to report insecure visa status $(B=1.66, S E=0.49, p<0.001)$. Individuals in the high- and very-high-symptom groups were almost twice as likely to be female, and five times more likely to report insecure visa status than those in the low-symptom group.

\section{Discussion}

Visa insecurity was associated with a greater severity of mental health difficulties in a large clinical sample of asylum seekers and refugees. Those reporting insecure visa status were at least five times more likely to experience high or very-high-level symptoms of depression and 
Table 4 Predictors of latent profile group membership on the Hopkins Symptom Checklist across a clinical sample of refugees and people seeking asylum in Australia 2009-2015 $(n=781)$

\begin{tabular}{lccc}
\hline & $B$ & $S E$ & Odds \\
\hline Very high versus low & & & \\
Gender & $0.767^{*}$ & 0.305 & 1.96 \\
Interpreter & -0.174 & 0.401 & 0.84 \\
Visa & $1.662^{* *}$ & 0.490 & 5.27 \\
Age & 0.023 & 0.013 & 1.02 \\
SES & 0.001 & 0.002 & 1.00 \\
Time in Australia & 0.032 & 0.056 & 1.03 \\
High versus low & & & \\
Gender & $0.673^{* *}$ & 0.258 & 1.96 \\
Interpreter & $0.647^{*}$ & 0.323 & 0.52 \\
Visa & $1.769^{* * *}$ & 0.444 & 5.86 \\
Age & 0.009 & 0.012 & 1.01 \\
SES & 0.003 & 0.002 & 1.00 \\
Time in Australia & 0.026 & 0.053 & 1.03 \\
Moderate versus low & & & \\
Gender & 0.436 & 0.273 & 1.55 \\
Interpreter & -0.618 & 0.341 & 0.54 \\
Visa & 0.740 & 0.489 & 2.10 \\
Age & -0.001 & 0.013 & 1.00 \\
SES & 0.002 & 0.002 & 1.00 \\
Time in Australia & 0.001 & 0.06 & 1.00 \\
\hline
\end{tabular}

$S E$ standard error, SES socio-economic status

$* p<0.05 ; * * p<0.01 ; * * * p<0.001$

anxiety than those with permanent residency or citizenship. Women in the sample were twice as likely to report high or very high levels of distress compared to men. This study extends the evidence base beyond previous findings by highlighting the harmful effects of visa insecurity in the largest sample of refugees from multiple backgrounds assessed to date. The findings raise serious concerns for emergent shifts towards temporary protection visas in national and international migration policies. An emphasis on temporary visas for asylum seekers has potential for detrimental effects, particularly among women, and slow processing times for refugee determination prolongs the period of uncertainty and insecurity.

Augmenting prior investigations of the effects of restrictive visa policies, the findings extend a growing body of evidence demonstrating the role of insecure visa status in health, social integration, and livelihood outcomes. Beyond the detrimental effects on psychological outcomes, temporary visas have been associated with difficulties in acquiring new language skills (Steel et al. 2011b), prolonged isolation (Johnston et al. 2009; Steel et al. 2011b), a lack of agency (Kenny et al. 2016), difficulties addressing resettlement stressors (Nickerson et al. 2011; Steel et al. 2011b), and a sense of uncertainty and anxiety for the future (Johnston et al. 2009; Procter et al. 2018). These difficulties have been measured longitudinally (Nickerson et al. 2011; Steel et al. 2011b) and demonstrate a widening gap in psychological outcomes between people with temporary and permanent protection. In Switzerland, recent data indicate that delays in processing asylum claims reduce subsequent engagement in employment, an effect that is consistent across socio-demographic factors and countries of origin (Hainmueller et al. 2016). The pattern of findings suggests that reductions in workforce participation in this group relate to psychological mechanisms rather than skill atrophy (Hainmueller et al. 2016). Expanding evidence for refugee integration reflects a larger literature on migrant participation, which has demonstrated the beneficial effects of an efficient pathway to naturalization and citizenship in improving workforce participation, social integration, and belonging in the country of resettlement (Hainmueller et al. 2017; Nunn et al. 2016). Overall, these findings highlight the distinctive mental health needs of individuals who hold temporary status in resettlement countries.

Resettlement challenges may be heightened for women in particular. Women and girls are at greater risk of a broad range of severe traumatic exposures and exploitation in conflict settings (Betancourt et al. 2013) and during the migrant journey (Digidiki and Bhabha 2017). In many cases, the challenges continue upon resettlement (Wachter et al. 2016). Access to services, including culturally sensitive healthcare, can be problematic, and a strong perception of discrimination persists in a number of resettled communities (Fozdar and Hartley 2013). A particularly vulnerable subset is women with small children, who may be more likely to be socially isolated, and have difficulty accessing language classes, psychological treatment, legal and health services, employment, and community supports (Wachter et al. 2016). The current findings extend Johnston and colleagues' (2009) assessment, in which temporary visa status and female gender were associated with increased rates of mental health problems among Iraqi refugees. The ongoing adversities that refugee women face during resettlement are an important focus for future research, policy, and health services.

Clinical challenges are likely to arise while clients are unable to successfully engage in resettlement activities. The prolonged uncertainty associated with visa insecurity, and resulting sense of hopelessness, despair, and anxiety (Nickerson et al. 2011; Slobodin et al. 2018) have potential to hamper the treatment process. Interruptions and delays to visa processing may exacerbate the chronicity of traumatic experiences, ongoing uncertainty and overwhelming sense of burdensomeness to oneself and others, that can hinder treatment progress and place clients at risk of 
suicide (Procter et al. 2018). People seeking asylum may report higher levels of social isolation, a sense of thwarted purpose, and fractured identity (Ellis et al. 2015) that are exacerbated by the visa assessment process (Procter et al. 2018) and may restrict access to or engagement in psychological services. For those who have resettled with families, there may be some members who receive permanency, while others do not (based on date of arrival), creating tension and stress within the family unit. Although the legal implications of visa assessment are not often a focus of treatment, it is important that clinicians are aware of the heightened mental health needs of this population and that treatment goals may be limited to maintenance of gains or preservation of hope during periods of visa assessment. However, recent evidence suggests that visa insecurity may not directly affect treatment response for people seeking asylum (Haagen et al. 2017), with promising implications for clinical practice. The current findings indicate that a combination of clinical and community services that enhance a sense of belonging and connection will be particularly important in advancing psychological recovery during times of uncertainty.

\section{Limitations}

The study has several limitations. First, the broad range of nationalities included in the sample means that a large number of languages were represented. Interpreters assisted $74.8 \%$ of the sample in completing the questionnaires, which extends the findings to groups that have not been included in prior research in this field, but may have implications for the reliability and validity of the items. Second, it was not possible to determine a response rate, as the sample comprised consecutive cases attending a service for torture and trauma rehabilitation in Australia and noncompletion numbers were not systematically recorded. However, the sample was largely representative of the broader refugee and asylum seeking population in Australia at the time (Department of Immigration and Border Protection 2014), although our sample had a higher representation of women in the insecure visa groups (Australian Border Force 2017). A clinical sample may denote higher rates of psychiatric illness; however, there is a possibility that many people holding temporary visas or awaiting determination may have limited or no access to psychological services, despite a substantial level of need. Third, it may be the case that symptoms were over- or under-reported by clients. Over-reporting may occur if someone believes that higher symptom levels will increase access to services, and strengthen or expedite their asylum claim, although prior findings suggest that this pattern of reporting is rare (Keller et al. 2003). In contrast, underreporting is common among traumatized populations who may have concerns about stigma or experience difficulty engaging with standardized assessments of psychological health. Fourth, only one measure of psychological distress was used in the current study and additional measures, including those that assess post-traumatic stress symptoms would have improved the study. Finally, the use of crosssectional data limits our ability to infer causality, and thus, future research should aim to utilize longitudinal and quasiexperimental methods. It is possible that worsened mental health plays an important role in preventing or delaying engagement with asylum applications. Longitudinal studies that illuminate trajectories of adjustment, or optimal points for clinical intervention, would be highly valuable.

\section{Conclusions}

Governments have a unique opportunity to strengthen the process of resettlement and improve mental health outcomes through coordinated evidence-based migration policy (Kousoulis et al. 2017). Timely progression to permanent visa status will ensure that people with refugee backgrounds maintain good psychological health, increase economic participation, and connect with opportunities for social and community engagement (Hainmueller et al. 2017; Nunn et al. 2016). In contrast, delaying visa determinations for people seeking asylum is likely to exacerbate clinical needs and resettlement difficulties. Intervention that addresses the psychological consequences of dislocation from permanent resettlement will be critical. A renewed emphasis on supporting timely processing of asylum claims, and transitioning to permanent visa status will have cascading benefits for the mental health of a cohort of people seeking asylum who face continued psychological risk.

Acknowledgements We are grateful to the ASeTTS clinical team, coordinators, and clients whose input and experience have informed the study. We thank Grace McKie for her assistance with data management.

Funding The study was funded by a University of Western Australia Collaborative Research Grant and Western Australian Government Department of Health New Independent Researcher Infrastructure Award. The first author was supported by a National Health and Medical Research Council of Australia (NHMRC) Sidney Sax Early Career Fellowship (GNT1035196) and a Curtin Research Fellowship. The funding bodies played no role in the design, analysis, interpretation of findings, or decision to publish the study.

\section{Compliance with ethical standards}

Conflict of interest The second and third authors were employed by an agency that provides psychological services for torture and trauma survivors. The authors declare no other conflicts of interest. 
Ethics statement All procedures performed in studies involving human participants were in accordance with the ethical standards of the University of Western Australia Human Research Ethics Committee and with the 1964 Helsinki Declaration and its later amendments or comparable ethical standards.

\section{References}

Australian Border Force (2017) Illegal maritime arrivals on bridging visa E: March 2017. Commonwealth of Australia, Canberra

Betancourt TS, Newnham EA, McBain R, Brennan RT (2013) Posttraumatic stress symptoms among former child soldiers in Sierra Leone: follow-up study. Br J Psychiatry 203:196-202

Carswell K, Blackburn P, Barker C (2011) The relationship between trauma, post-migration problems and the psychological wellbeing of refugees and asylum seekers. Int $\mathrm{J}$ Soc Psychiatry 57:107-119

Department of Immigration and Border Protection (2014) Asylum statistics Australia: quarterly tables-June quarter 2014. Australian Government, Canberra

Digidiki V, Bhabha J (2017) Emergency within an emergency: The growing epidemic of sexual exploitation and abuse of migrant children in Greece. FXB Center for Health and Human Rights, Harvard University, Boston

Dudley MJ, Procter NG, Newman LK (2011) Suicide and self-harm in immigration detention. The Medical Journal of Australia 195:582

Ellis BH, Lankau EW, Ao T et al (2015) Understanding Bhutanese refugee suicide through the interpersonal-psychological theory of suicidal behavior. Am J Orthopsychiatry 85:43

Fazel M, Karunakara U, Newnham EA (2014) Detention, denial, and death: migration hazards for refugee children. Lancet Glob Health 2:e313-e314

Fozdar F, Hartley L (2013) Refugee resettlement in Australia: what we know and need to know. Refug Surv Q 32:23-51

Galatzer-Levy I, Nickerson A, Litz B, Marmar C (2013) Patterns of lifetime PTSD comorbidity: a latent class analysis. Depress Anxiety 30:489-496

Haagen JF, Heide F, Mooren TM, Knipscheer JW, Kleber RJ (2017) Predicting post-traumatic stress disorder treatment response in refugees: multilevel analysis. Br J Clin Psychol 56:69-83

Hainmueller J, Hangartner D, Lawrence D (2016) When lives are put on hold: lengthy asylum processes decrease employment among refugees. Sci Adv 2:e1600432

Hainmueller J, Hangartner D, Pietrantuono G (2017) Catalyst or crown: does naturalization promote the long-term social integration of immigrants? Am Polit Sci Rev 111:256-276

Hesbacher PT, Rickels K, Morris RJ, Newman H, Rosenfeld H (1980) Psychiatric illness in family practice. J Clin Psychiatry 4:6-10

Hocking DC, Kennedy GA, Sundram S (2015) Mental disorders in asylum seekers: the role of the refugee determination process and employment. J Nerv Ment Dis 203:28-32

Hollifield M, Warner TD, Lian N et al (2002) Measuring trauma and health status in refugees: a critical review. J Am Med Assoc 288:611-621

Hollings J, Samuilova M, Petrova-Benedict R (2012) Health, migration and border management: analysis and capacitybuilding at Europe's borders. Int J Public Health 57:363-369. https://doi.org/10.1007/s00038-011-0319-8

Johnston V, Allotey P, Mulholland K, Markovic M (2009) Measuring the health impact of human rights violations related to Australian asylum policies and practices: a mixed methods study. BMC Int Health Hum Rights 9:1-12
Karlsen E (2016) Refugee resettlement to Australia: what are the facts?. Government of Australia Department of Parliamentary Services, Canberra

Keller AS, Rosenfeld B, Trinh-Shevrin C et al (2003) Mental health of detained asylum seekers. Lancet 362:1721-1723

Kenny MA, Procter NG, Grech C (2016) Mental health and legal representation for asylum seekers in the "Legacy caseload". Cosmop Civ Soc: Interdiscip J 8:84-103

Kousoulis AA, Ioakeim-Ioannidou M, Economopoulos KP (2017) Refugee crisis in Greece: not a one-country job. Int $\mathrm{J}$ Public Health 62:1-2. https://doi.org/10.1007/s00038-016-0890-0

Laban CJ, Gernaat HB, Komproe IH, Schreuders BA, De Jong JT (2004) Impact of a long asylum procedure on the prevalence of psychiatric disorders in Iraqi asylum seekers in The Netherlands. J Nerv Ment Dis 192:843-851

Marsh HW, Lüdtke O, Trautwein U, Morin AJS (2009) Classical latent profile analysis of academic self-concept dimensions: synergy of person- and variable-centered approaches to theoretical models of self-concept. Struct Equ Model: Multidiscip J 16:191-225. https://doi.org/10.1080/10705510902751010

Morgan G, Melluish S, Welham A (2017) Exploring the relationship between postmigratory stressors and mental health for asylum seekers and refused asylum seekers in the UK. Transcult Psychiatry 54:653-674

Muthén LK, Muthén BO (2010) Mplus user's guide, 6th edn. Muthén \& Muthén, Los Angeles

Newnham EA, Balsari S, Lam RPK, Kashyap S, Pham P, Chan EYY, Patrick K, Leaning J (2017) Self-efficacy and barriers to disaster evacuation in Hong Kong. Int J Public Health 62:1051-1058. https://doi.org/10.1007/s00038-017-1036-8

Nickerson A, Steel Z, Bryant R, Brooks R, Silove DM (2011) Change in visa status amongst Mandean refugees: relationship to psychological symptoms and living difficulties. Psychiatry Res 187:267-274

Nunn C, McMichael C, Gifford SM, Correa-Velez I (2016) Mobility and security: the perceived benefits of citizenship for resettled young people from refugee backgrounds. J Ethn Migr Stud 42:382-399

Nylund KL, Asparouhov T, Muthén BO (2007) Deciding on the number of classes in latent class analysis and growth mixture modeling: a Monte Carlo simulation study. Struct Equ Model: Multidiscip J 14:535-569

Pastor DA, Barron KE, Miller BJ, Davis SL (2007) A latent profile analysis of college students' achievement goal orientation. Contemp Educ Psychol 32:8-47. https://doi.org/10.1016/j.cedp sych.2006.10.003

Phillips J (2014) Boat arrivals in Australia: a quick guide to the statistics. Pariliament of Australia, Canberra

Phillips J, Spinks H (2013) Immigration detention in Australia. Parliament of Australia, Department of Parliamentary Services, Canberra

Procter NG, Kenny MA, Eaton H, Grech C (2018) Lethal hopelessness: understanding and responding to asylum seeker distress and mental deterioration. Int J Ment Health Nurs 27:448-454

Robjant K, Robbins I, Senior V (2009) Psychological distress amongst immigration detainees: a cross-sectional questionnaire study. Br J Clin Psychol 48:275-286

Schick M, Morina N, Mistridis P, Schnyder U, Bryant RA, Nickerson A (2018) Changes in post-migration living difficulties predict treatment outcome in traumatized refugees. Front Psychiatry 9:476

Slobodin O, Ghane S, De Jong JT (2018) Developing a culturally sensitive mental health intervention for asylum seekers in the Netherlands: a pilot study. Intervention 16:86 
Steel Z et al (2004) Psychiatric status of asylum seeker families held for a protracted period in a remote detention centre in Australia. Aust N Z J Public Health 28:527-536

Steel Z, Liddell BJ, Bateman-Steel CR, Zwi AB (2011a) Global protection and the health impact of migration interception. PLoS Med 8:e1001038

Steel Z, Momartin S, Silove DM, Coello M, Aroche J, Tay KW (2011b) Two year psychosocial and mental health outcomes for refugees subjected to restrictive or supportive immigration policies. Soc Sci Med 72:1149-1156

UNHCR (2018) Global trends: forced displacement in 2017. UNHCR, Geneva

Vonnahme LA, Lankau EW, Ao T, Shetty S, Cardozo BL (2015)
Factors associated with symptoms of depression among Bhutanese refugees in the United States. J Immigr Minor Health 17:1705-1714

Wachter K, Heffron LC, Snyder S, Nsonwu MB, Busch-Armendariz NB (2016) Unsettled integration: pre-and post-migration factors in Congolese refugee women's resettlement experiences in the United States. Int Soc Work 59:875-889

Publisher's Note Springer Nature remains neutral with regard to jurisdictional claims in published maps and institutional affiliations. 